\title{
Transmutations in Masquerade Costumes and Performances: An Examination of Abuja Carnival 2010
}

\author{
Alex C. Asigbo*
}

\begin{abstract}
Masquerades or spirit manifests are uniquely ritualistic. Masquerade performances in African culture are symbolizations; they represent not only the physical and continuous presence of the ancestors but also their luminal sense of justice and equity. Masquerade, derived from mask presupposes that somebody's identity is concealed with costumes and sometimes, makeup. Since costuming is the most essential and significant element in the masquerade art, this study tries to understand how performance context and purpose can mediate the form or costume which a masquerade wears. Being highly ritualized, how does its socialization impact on its costuming and vice versa? Indeed, how does technology and commerce mediate the ritual content of costume especially since carnival atmosphere and purposes require a large number of participants hence the need to build costumes for a large number of people? Again, the argument that masquerades as representations of the ancestors must adapt and change to be in the image of a $21^{\text {st }}$ century ancestor might be invoked to justify the transmutations in contemporary masquerade costumes.

http://dx.doi.org/10.4314/ujah.v13i1.1
\end{abstract}

\section{Introduction}

The phenomenon of Masquerades, Spirit manifests or Ancestral masks in most places in Africa, has continued to be shrouded in mystery. This is more so in view of the fact that donning the ancestral mask is almost always, an exclusive act. Seen as symbolization and manifestation of the continuing relationship between the living and the dead, masquerades continue to play a vital role in the life of many African 
societies. We thus have different types of masquerades for various purposes ranging from those that entertain to those that fulfill ritual functions and those that are used for war or for the enforcement of justice. Judging by the pivotal role masquerades play in African life, one must therefore of necessity investigate the origin(s) of that phenomenon.

To non Africans, the sight of a "masked man" might be interpreted to mean a simple disguise, an eccentric or in fact, a clown catching his fun; but to the African, masking is a serious engagement that requires not only mental and physical alertness but also, spiritual fortification. This is because, ancestral masks or spirit manifests are not mere human beings but manifestations from the spirit realm - of the ancestors and other disembodied beings seeking communion with mortals. This is why masked spirits depending on their purpose and function possess attributes ranging from spiritual (in) sight, clairvoyance, agility, unusual strength, and so on. Spirit manifests command ultimate respect not just because of their ethereal presence but because they are believed to embody supernatural wisdom, strength and purity hence they are above the imperfections of mundane man.

Masquerade studies have attracted serious attention from many scholars of African cultures. These scholars have been concerned not only with masquerade costumes and speech but also its place in the peoples' socio-political and judicial life. Thus, from Ugonna Nnabuenyi, J.S. Illah, Robin Horton, Onuora Nzekwu, Jenkeri Okwori, and James Amankulor through to Romanus Egudu's seminal work on masquerade speeches...Poetry of the Living Dead, the ritual and sociology of the masquerade art has received and is still receiving robust attention as scholars continue to ponder this uniquely African heritage. Even though the masquerade art is more than mere costume, costume remains the cornerstone upon which all other elements of the masquerade hinge. 
As ritual and symbolization, spirit manifests maybe associated with specific culture areas but as art, it is increasingly becoming ubiquitous to all Nigerian cultures. This is because, as ritual and symbolization, it fulfils specific functions in the day to day existence of the people who understand its significance hence the veneration and high esteem accorded it as physical manifestations of the spirit world; emissaries of the dead to the living world and incorrigible judges and enforcers of divine judgments. As art however, it is merely adroit combination of costume and make-up with a touch of flexibility on the part of the masker. This is why the explosion in Carnivals is fast turning the masking tradition into a national pastime that can no longer be said to belong to specific culture areas. Since Carnivals are about possibilities as against cultural festivals that celebrate what already is in existence, it is not surprising that the Abuja Carnival should be a breeding ground for robust and wacky costume combinations in the masquerade art. This is because, culture workers desirous of bringing specific masquerades to the Carnival go the extra mile to make sure that what they bring to the Carnival are not what is but what could be hence sometimes, color and concept combinations in the masquerade costumes may be anachronistic. Commerce also plays an important role in designing costumes for carnival outings in the light of the fact that designers design to meet deadlines and conform to set themes while maximizing profit.

\section{Possible Origins of the Masquerade Art}

Various theories of origin exist each trying to explain how masquerades came about. The first of these is:

\section{The Power Balancing Theory}

Many African communities practice witchcraft which is said to be dominated by women, who supposedly, use it to oppress and intimidate the men folk especially at night. To provide a 
counter force to this supposed conspiracy by women, the men folk got together and decided to form the masquerade cult from which women were generally excluded. Thus, whenever witches cried at night and something untoward happened, masquerades are usually summoned to unravel or unmask the faces behind such acts. Thus, knowing that there is an external power waiting to expose them, witches are said to become more careful. Masquerades therefore perform certain social control functions by enforcing discipline and upholding natural law. The powers of the masquerade cult are such that even kings are under their authority since they are believed to be agents of supernatural wisdom. Supporting this, Ododo maintains:

The tremendous power women (sic) wild and their fearful capacity as witches have therefore been positioned as the key reason why the men folk instituted the masquerade art and logically exclude female overt participation in the night performance of Eku' rahu (masquerade). (107).

\section{The omnipresent theory}

Masquerades are believed to be ancestors in many cultures where the masquerade tradition exists. They are seen as ancestors on momentary sally to the world of the living. This belief stems from the cosmic view of the African world which conceives of the world as cyclical, tripartite and interdependent, with each plain of existence believed to be incomplete without the company of the next. Thus, the ancestors overcome by an incomprehensible nostalgia and yearning for the company of man, manifest as masquerades to commune with the living. In such cases, these masquerades exhibit the characteristics of specific ancestors and can as the occasion demands, foretell the future and perform other ritual functions. Spirit manifests are thus, physical manifestations of 
the continuous presence and interest of the ancestors in the affairs of the living. In Igbo folk stories, masquerades are said to manifest from ant holes or groves far removed from prying eyes. Confirming the usual sally of the ancestors to the world of the living, Illah says:

...the ancestors are believed to travel back to the living, through the mediant persona...to partake and celebrate with their living offspring, in a re-invigoration of their relationship, (8).

Masquerades are thus believed to be divinities, citizens of heaven who get involved in entertainment and edification through performance so as to balance individual and societal emotions. (Ogundeji, 21-22). In doing this, vices are purged even as social control is asserted since the masquerades speak with the authority of the ancestors.

\section{Culture versus Carnival}

Culture has been variously described as a way of life or the shared beliefs, customs and behavior of a specific group of people often in specific locations. It is dynamic hence it develops and evolves. In a manner of speaking, culture can be regarded as that which already is hence even though it is said to be dynamic, it can equally connote tradition or that which does not easily change, hence its view as an accepted way of doing things. Carnival, on the other hand, is a costumed "street party" and connotes spectacle, elegance, gaiety, pageant, and dancing. While culture celebrates that which is, carnival celebrates that which could be. In other words, carnival celebrates possibilities and fantasies or where we could get to in the future.

Carnivals started in ancient societies as avenues for the release of pent up libidinous energies... a form of all fools day, where people are granted leave to poke fun at all societal 
institutions and dress outrageously to catch fun. The Abuja national carnival was started by the government of Chief Olusegun Obasanjo in the year 2005 with its arrowhead as the then Federal Capital Territory Minister, Mallam Nasir ElRufai. It was designed to be an avenue for the showcasing of the rich and diverse cultural heritage of the Nigerian nation, serve the much needed function of pulling in foreign exchange through promoting cultural tourism and promote unity through cultural integration.

Since Carnivals are designed to have themes and specific contents, the theme for Abuja Carnival 2010 was "Celebrate Nigeria". As a way of pandering to the tastes of our religious brothers and sisters, the organizers made sure to prohibit any display that could be attributed to ritual powers. In doing this, the ritual content of carnival masquerades is drastically reduced if not completely eradicated. Thus, every masquerade that displays during the carnival can be said to be a transmutation of the original crafted specifically to entertain. Even though transmutation in the masquerade art can be on two levels - that which transmutes the individual to a spirit incarnate as he puts on the costume and dons the mask head; and that which transmutes a spirit incarnate meant for ritual purposes to a mere entertainer, we are mainly concerned in this paper with the latter.

\section{Costume in the Masquerade Art}

The saying that "high walls do not make a prison, neither does a habit make a monk" does not apply to the masquerade art. For the masquerade art, costume is everything as there can be no masquerade without costume. Utoh- Ezeajugh defines costume as:

... the items of clothing, accessories and ornamentation worn by the actor or actress for the purpose of defining character and 
establishing the circumstances of the character's existence, by situating him/her in time and space, (130).

Continuing the discourse on the utilitarian value of costumes, Russell as quoted by Utoh-Ezeajugh describes costumes as:

... the moving scenery of a production, and when worn by the actors, who are the centre of all dramatic action, they are the strongest element of the visual scene; they project personality and individual emotion and obtain the strongest audience focus, (132).

Indeed, the characteristics or powers of a specific masquerade are most often, embedded in its costume and the mask head. Beyond its size, it is the color and variety of the Ijele masquerade head that makes it the king of Igbo masquerades. In the same way, the aura and mystery of the Odumodu masquerade is embedded in its costume and mask head. As a "True Listener", Odumodu can only read minds when it dons the mask head and stares into men's hearts. In spite of the above, the masquerade art is more than mere costuming hence the myth behind the masquerade performance is what makes it more than man - the personification of the luminal essence of our ancestors.

Social masquerades are known for their colorful costumes. Carnival masquerades are social masquerades hence there's a deliberate effort to exclude the most important element in a masquerade costume for ritual purposes. This element is called Ibobo or aura in the Igbo culture area and it is what transforms masquerades from mere cloth combination to spirits. It is the Ibobo that gives masquerades there forbidding presence and spiritual power. This will undeniably work against the purpose of carnivals which are meant to be street 
parties where people are free to mix and mingle at will. Thus, in designing masquerade costumes for carnivals, attempts are made to make them conform to theme and other utilitarian considerations like weight, functionality and ease of mass production as well as cost.

Perhaps, the most potent argument in justifying the transmutations in masquerade costumes not only for carnivals but also for masquerades generally will be the influence of technology and commerce in today's world. With technology leading to many inventions with notable and noticeable negative side effects, it is only natural that man, as a pragmatic being will try to adapt to be in tune with the spirit of the times. Nails, for instance, are a modern invention that can easily pierce the feet especially if left bare or covered with only stockings. It is an attempt to mitigate this untoward event of seeing a spirit manifest bleed that certain designers give them foot wears like canvass or shoes. Again, the hot sun against a tarred road is very unfriendly to soles of the feet hence the attempt to make sure that performers' feet are protected. (See fig 1.2, 3. Notice that instead of wearing just stockings, the masquerades from Bayelsa State also put on bath-room slippers to protect the maskers from the heat of the sun). 


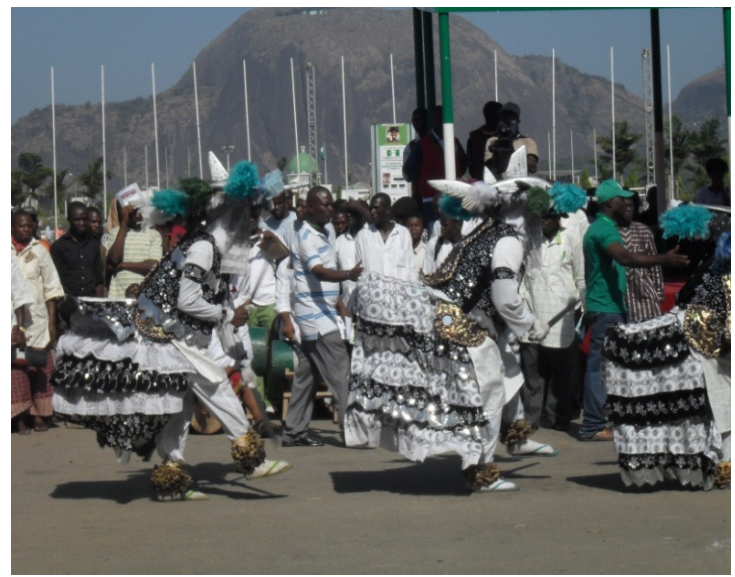

Fig. 1

Undoubtedly, the most significant transformation in the costumes of carnival masquerades is in the area of colour. As is known, the raison d'être of carnivals are spectacle and breath-taking colour combinations.

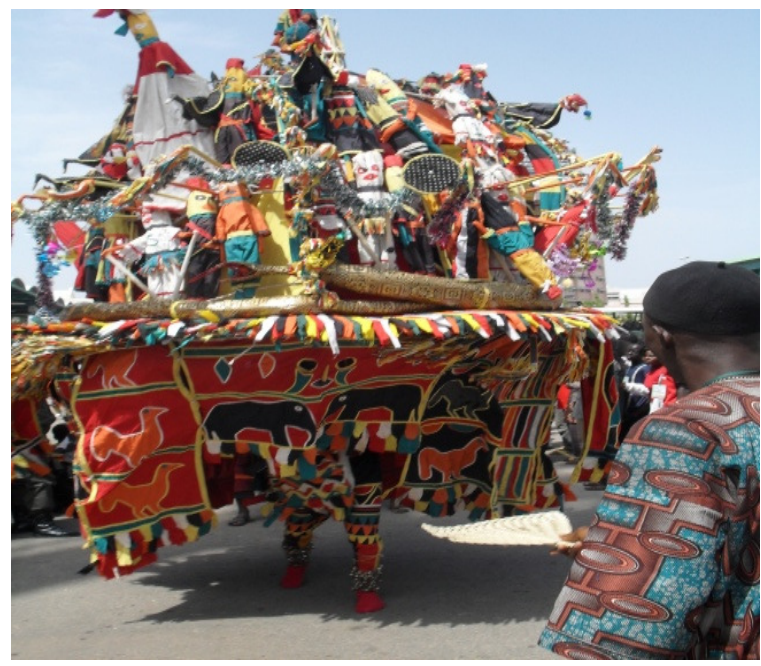

Fig. 2 
Commenting on the significance of colour in the African context, Utoh-Ezeajugh insists that:

... colours ... possess significant meanings which may vary from culture to culture. In contrast to Western costumes, there is often a deeper meaning hidden away in traditional Nigerian costume designs, (135).

Carnival masquerades thus aim to impress, capture and sustain the audience's attention through creative colour combinations instead of through magic or some other powers as may obtain in their traditional settings. Since carnivals usually have themes, costume designers are tasked to their wit's end as they struggle to conform to theme and at the same impress with colours.

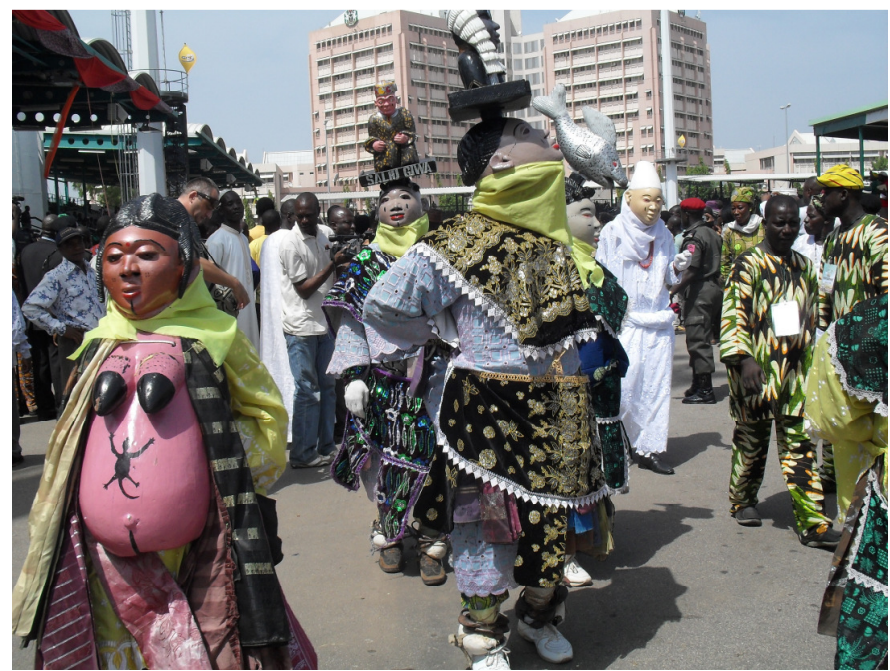

Fig. 3 


\section{Conclusion}

In all, one observes that performance context plays a major role in determining not only the colour combination but also the method of building the costume since designers most times, try as much as possible to make their designs functional. Carnivals being highly social events require very bright colours as can be seen from our sample masquerade pictures. We therefore submit that costume in the masquerade art for Abuja carnival 2010, witnessed a marked transmutation from what obtains in the various traditional settings where masquerades wore stockings or are even bare footed. The context of performance also mediated to a great extent, the foot wears of the various masquerades as designers take time to guard the performers' feet against the scorching heat of tar on Abuja roads. To combat this, masquerades wore different types of foot wears ranging from bathroom slippers to canvass shoes.

This publication was prepared with the support of an African Humanities Program fellowship, established by the American Council of Learned Societies and supported financially by the Carnegie Corporation of New York.

*Alex C. Asigbo is a Professor of Theatre Arts in the Department of Theatre Arts, Nnamdi Azikiwe University, Awka 


\section{Works Cited}

Adedeji, Joel. "Alarinjo: The Traditional Yoruba Travelling Theatre" in Drama and Theatre in

Nigeria: A Critical Source Book. Ed. Yemi Ogunbiyi. Lagos: Nigeria Magazine. (1981) 221-248.

Amankulor, James. "Ekpe Festival as Religious Ritual and Dance Drama" in Drama and Theatre in Nigeria: A Critical Source Book. Ed. Yemi Ogunbiyi. Lagos: Nigeria Magazine. (1981) 113-130.

Horn, Andrew. "Ritual Drama and Theatrical Performance: A Case of Bori Spirit Mediumship"

in Drama and Theatre in Nigeria: A Critical Source Book.

Ed. Yemi Ogunbiyi. Lagos: Nigeria Magazine. (1981) 181-202.

Horton, Robin. "The Gods as Guests: Aspects of Kalabari

Religious Life" in Drama and Theatre in Nigeria: A

Critical Source Book. Ed. Yemi Ogunbiyi. Lagos: Nigeria Magazine. (1981) 81-112.

Illah, John Egwugwu. "The Performing Arts of the Masquerade and its Changing Status in Igala." M.A. Dissertation of English and Drama Sub-unit, Ahmadu Bello University, Zaria. 1983.

Nzekwu, Onuora. "Masquerade" in Drama and Theatre in Nigeria: A Critical Source Book. Ed. Yemi Ogunbiyi. Lagos; Nigeria Magazine. (1981) 131-135.

Ododo, E. Sunday. "Gender Ambiguity and Iconic Paradox in Ebirra Ekuechi Facekuerade Ritualization" in Developments in the Theory and Practice of Contemporary Nigerian Drama and Theatre: A Festschrift in Honour of Dapo Adelugba. Eds. Duro Oni and Sola Adeyemi. United Kingdom: Rochester Press. 2011. 
Ogundeji, Philip. Ritual as Theatre, Theatre as Ritual: The Nigerian Example. Ibadan Monograph Series, Vol. 2 No.1. 2000.

Utoh-Ezeajugh, Tracie. "Promoting Minority Cultures Through Costume and Make-up: Sam Ukala's Break a Boil in Production" in Theatre and Minority Rights: Perspectives on the Niger Delta. Ed. Austin Ovigue Asagba. Ibadan: Kraft Books Ltd. 2010.

Ugonna, Nnabuenyi. "Ezeigboezue: An Igbo Masquerade Play" in Drama and Theatre in Nigeria: A Critical Source Book. Ed. Yemi Ogunbiyi. Lagos: Nigeria Magazine. (1981) 495- 503. 